\title{
ANALISIS HUBUNGAN INISIASI MENYUSU DINI TERHADAP PEMBERIAN ASI EKSKLUSIF DI WILAYAH KERJA PUSKESMAS MAKRAYU KOTA PALEMBANG
}

\author{
Nina Deslima ${ }^{1}$, Misnaniarti ${ }^{2}$, HM. Zulkarnain ${ }^{3}$ \\ ${ }^{1,2,3}$ Departemen Administrasi Kebijakan Kesehatan, Magister Kesehatan Masyarakat \\ Fakultas kesehatan Masyarakat Universitas Sriwijaya \\ Email : ninadeslima05@gmail.com¹, misnaniarti@ unsri.ac.id ${ }^{2}$, septi_2003@yahoo.com ${ }^{3}$
}

\begin{abstract}
Early initiation of breastfeeding (IMD) is one of the government's policy can reduce the neonatal mortality rate (AKN) and increase the coverage of exclusive breastfeeding. Scope IMD and exclusive breastfeeding is low based on the data contained within the Department of Health in Palembang. The purpose of this research to analyze the relationship between Early Initiation of Breastfeeding (IMD) on exclusive breastfeeding in some Health Center Makrayu, Palembang. This research was conducted in September 2018. The study population amounted to 1,177 mothers. The research sample as many as 110 people by using purposive sampling. This study using quantitative methods, with cross-sectional design. Data collection instruments such as questionnaires, interviews, and observations as well as data with multiple logistic regression analysis. Result dan Conclusion: The results showed that there was a relationship Early Initiation of Breastfeeding $(I M D)(p=0.001)$; education ( $p=0.023)$; family support ( $p=0.003$ on exclusive breastfeeding. Multivariat analyzed showed that dominant risk factor of early initiation of breastfeeding is early initiation of breastfeeding (IMD) $(p=0,045)$.
\end{abstract}

Keyword : Early Initiation of Breastfeeding (IMD), Exclusive Breastfeeding, family support, Education.

\section{PENDAHULUAN}

Di Negara-negara berkembang malnutrisi merupakan salah satu masalah kesehatan. Proporsinya 70\% di Asia, $26 \%$ di Afrika dan 4\% di Amerika Latin dan Caribbean. Diperkirakan 80\% dari jumlah ibu yang melahirkan mampu untuk menghasilkan air susu ibu dalam jumlah yang cukup untuk keperluan bayinya secara penuh tanpa makanan tambahan bahkan ibu yang gizinya kurang baikpun dapat menghasilkan ASI cukup tanpa makanan tambahan. Berdasarkan penelitian WHO (2000) di enam Negara berkembang, resiko kematian bayi antara usia 9-12 bulan meningkat $40 \%$ jika bayi tersebut tidak disusui, untuk bayi berusia dibawah 6 bulan angka kematian meningkat menjadi 48\% dengan Pemberian ASI eksklusif dapat mencegah kematian balita sebanyak 13\% (Roesli, 2008).

Survei Demografi dan Kesehatan Indonesia (SDKI) pada tahun 2012 
melaporkan bahwa 96\% anak di bawah umur 2 tahun di Indonesia telah mendapat ASI. Namun, hanya 50\% yang mendapat ASI dalam satu jam pertama setelah lahir dan hanya $66 \%$ yang mendapat ASI dalam hari pertama setelah lahir. Prevalensi inisiasi menyusu dini di Indonesia sendiri masih lebih 4 rendah yaitu 39\%. Angka itu masih jauh tertinggal bila dibandingkan dengan negara-negara berkembang lain seperti Oman (85\%), Sri Lanka (75\%), dan Filipina (54\%) (Statistic Indonesia and Macro International, 2008). Hal ini menunjukkan program IMD di Indonesia belum terlaksana secara optimal.

Peraturan Pemerintah Nomor 33 Tahun 2012 menginstruksikan kepada pemerintah daerah dan swasta untuk bekerjasama mendukung pemberian ASI Eksklusif dan Inisiasi Menyusu Dini (IMD). Melalui Peraturan Pemerintah, Pemerintah memformalkan hak perempuan untuk menyusui (termasuk di tempat kerja) dan melarang promosi pengganti ASI. Pemberian ASI Eksklusif dan IMD bertujuan untuk memenuhi kebutuhan nutrisi bayi dan mencegah kekurangan gizi pada balita. Pemerintah menyarankan daerah untuk menyediakan fasilitas khusus ibu menyusui di tempat kerja agar ibu tetap bisa menyusui bayinya (Kemenkes RI, 2015).

Penelitian di Ghana yang dilakukan oleh Edmond (2006) dengan melibatkan 10.947 bayi menyatakan bahwa kesempatan menyusu dalam satu jam pertama dengan dibiarkan kontak kulit ke kulit ibu (setidaknya selama satu jam) maka $22 \%$ nyawa bayi dibawah 28 hari dapat diselamatkan. Menurut Roesli (2012) presentase kematian balita dapat dicegah dengan beberapa intervensi yaitu IMD, menyusui eksklusif enam bulan dan diteruskan dengan memberikan makanan pendamping ASI (MP-ASI). IMD dapat mengurangi 22\% kematian bayi 28 hari dari sekitar $40 \%$ kematian balita yang terjadi pada satu bulan pertama kehidupan bayi. Berarti IMD mengurangi angka kematian balita 88\% (Roesli, 2012).

Berdasarkan data Riskesdas 2013 Untuk presentase IMD di Sumatera Selatan sendiri yaitu sebesar $29,5 \%$ (Riskesdas, 2013). Di kota Palembang jumlah jumlah bayi yang IMD pada tahun 2016 yaitu sebanyak 39,9\%, sedangkan pada tahun 2017 jumlah bayi yang IMD pada tahun 2017 yaitu sebesar 59,5\%. Dapat di lihat dari data di atas bahwa cakupan pelaksanaan IMD di Kota Palembang mengalami kenaikan. Meskipun begitu angka cakupan ASI 
Eksklusif di kota Palembang sendiri masih rendah bahkan mengalami penurunan dimana pada tahun 2015 jumlah yang di beri ASI Eksklusif sebanyak 9,492 (72.91\%) sedangkan pada tahun 2016 yaitu bayi yang diberi ASI eksklusif adalah sebanyak 9,388 (68.60\%)sehingga perlu adanya upaya untuk meningkatkan keberhasilan program ASI Eksklusif tersebut.

Rendahnya cakupan pemberian ASI Eksklusif 0-6 bulan dapat disebabkan masih kurangnya pemahaman masyarakat bahkan petugas kesehatan tentang manfaat dan pentingnya pemberian ASI Eksklusif kepada bayi usia 0-6 bulan, adanya promosi yang intensif susu formula, pemantauan sulit dilakukan, pencatatan dan pelaporan yang kurang tepat, masih kurangnya tenaga konselor ASI di lapangan, RS, Klinik Bersalin belum sayang bayi, belum adanya sanksi tegas bagi RS/Klinik Bersalin/Bidan Praktek Swasta yang belum sayang bayi, dan masih banyak RS yang belum melakukan rawat gabung antara ibu dan bayinya, serta masih rendahnya Inisiasi Menyusu Dini (IMD) (Profil Dinkes Provinsi Sumsel, 2016).

Berdasarkan data dari Puskesmas Makrayu kota Palembang jumlah bayi
IMD pada tahun 2016 yaitu sebesar $45,4 \%$, jumlah bayi yang IMD mengalami peningkatan pada tahun 2017 yaitu sebesar 97,3\%. Sedangkan angka cakupan ASI Eksklusif di Puskesmas Makrayu Palembang sendiri masih rendah bahkan mengalami penurunan dimana pada tahun 2016 jumlah bayi yang di beri ASI Eksklusif sebanyak $67,4 \%$ sedangkan pada tahun 2016 yaitu bayi yang diberi ASI eksklusif adalah sebanyak 63,6\%. Dapat dilihat dari data diatas bahwa persentase ASI eksklusif di Puskesmas Makrayu sendiri masih dibawah angka nasional.

\section{METODE PENELITIAN}

\section{Desain dan Sampel}

Penelitian ini merupakan penelitian deskriptif analitik dengan menggunakan rancangan cross sectional. Rancangan studi cross sectional yaitu suatu penelitian untuk mengetahui hubungan inisiasi menyusui dini (IMD) terhadap pemberian ASI Eksklusif dimana pengukuran variabel dilakukan dalam waktu yang bersamaan (Notoatmodjo, 2012).

Besar sampel dihitung dengan menggunakan rumus besar sampel desain cross sectional menggunakan rumus Lemeshow, yaitu : 


$$
\begin{gathered}
n=\frac{\left(z_{1-\propto \sqrt{2 \bar{P}(1-\bar{P})}+z_{1-\beta} \sqrt{P_{1}\left(1-P_{1}\right)+P_{2}\left(1-P_{2}\right)}}\right)^{2}}{\left(P_{1-} P_{2}\right)^{2}} \\
n=\frac{(1,96 \sqrt{0,50(0,50)}+1,64 \sqrt{0,51+(0,51)+0,49(0,49)})^{2}}{0,0529} \\
n=\frac{1,2936+0,687324}{0,0529} \\
n=54,6 \\
\text { Jumlah sampel yang didapatkan }
\end{gathered}
$$
adalah 55 orang, dikalikan 2 menjadi 110 sampel.

Keterangan :

n : Jumlah Sampel

Z1- $\alpha / 2$ : Derivat baku alpha $5 \%=1,96$

Z1- $\beta$ : Derivat baku beta kekuatan uji

$95 \%=1,64$

$\mathrm{P}^{-} \quad:(\mathrm{P} 1+\mathrm{P} 2): 2=0,5$

P1 : Proporsi ibu yang melakukan

IMD terhadap ASI Eksklusif 51\% (0,59)

(Ulandari, 2016).

P2 : Proporsi ibu yang tidak melakukan IMD terhadap ASI Eksklusif 49\% (0,41) (Ulandari, 2016).

Pengambilan sampel penelitian ini dilakukan dengan metode Purposive Sampling.

Kriteria Inklusi:

a. Ibu yang memiliki bayi berusia $\geq 7$ bulan

b. Ibu yang berdomisili di wilayah kerja Puskesmas Makrayu

c. Ibu bayi yang datang ke Posyandu Puskesmas Makrayu d. Ibu bersedia melakukan wawancara sebagai responden dengan mengisi inform consent

Kriteria Eksklusi:

a. Ibu yang sedang sakit

b. Ibu yang memiliki kontraindikasi menyusui

\section{Prosedur Penelitian}

Pengumpulan data variabel bebas dan terikat dengan menggunakan kuesioner. Kuesioner yang terlebih dahulu divalidasi dan harus reliabel. Instrumen kuesioner yang akan dirancang terdapat lima alternatif jawaban dan di setiap alternatif jawaban terdapat skor. Data yang akan diambil kemudian dikelompokkan ke dalam skala Likert. Skala Likert digunakan untuk mengukur sikap dan pendapat orang tentang fenomena sosial (Sugiyono, 2014).

\section{Analisis Data}

Analisis univariat dan analisis bivariat dilakukan dengan uji statistik chi-square dengan alpha 5\%. Analisis Multivariat dengan regresi logistik biner. Ho: Terdapat hubungan IMD, Pendidikan, dan dukungan keluarga, terhadap Pemberian ASI Eksklusif di wilayah kerja Puskesmas Makrayu Kota Palembang. 


\section{HASIL DAN PEMBAHASAN}

Analisis univariat pada penelitian ini meliputi variabel dependen yaitu Pemberian ASI eksklusif dan variabel independen yaitu Inisiasi Menyusu Dini.

\section{Analisis Univariat}

Tabel 1 Distribusi Frekuensi Variabel Independen dan Dependen

\begin{tabular}{|c|c|c|c|}
\hline \multirow{2}{*}{ Variabel } & \multirow{2}{*}{ Hasil Ukur } & \multicolumn{2}{|c|}{ Jumlah Sampel } \\
\hline & & $\mathbf{N}$ & $\%$ \\
\hline \multirow{4}{*}{$\begin{array}{c}\text { Pemberian ASI } \\
\text { Eksklusif }\end{array}$} & Tidak ASI & 86 & $78,2 \%$ \\
\hline & Eksklusif & & \\
\hline & ASI & 24 & $21,8 \%$ \\
\hline & Eksklusif & & \\
\hline Inisiasi & Tidak IMD & 82 & $74,5 \%$ \\
\hline $\begin{array}{l}\text { Menyusu Dini } \\
\text { (IMD) }\end{array}$ & IMD & 28 & $25,5 \%$ \\
\hline \multirow[b]{2}{*}{ Pendidikan } & Rendah & 32 & $29,1 \%$ \\
\hline & Tinggi & 78 & $70,9 \%$ \\
\hline \multirow{3}{*}{ Pekerjaan } & Bekerja & 27 & $24,5 \%$ \\
\hline & Tidak & 83 & $75,5 \%$ \\
\hline & Bekerja & & \\
\hline \multirow[b]{2}{*}{ Pendapatan } & Rendah & 32 & $29,1 \%$ \\
\hline & Tinggi & 78 & $70,9 \%$ \\
\hline \multirow{3}{*}{$\begin{array}{l}\text { Dukungan } \\
\text { Keluarga }\end{array}$} & Tidak & 28 & $25,5 \%$ \\
\hline & Mendukung & & \\
\hline & Mendukung & 82 & $74,5 \%$ \\
\hline Jumlah & & 110 & 100 \\
\hline
\end{tabular}

Analisis Bivariat

Tabel 2 Hubungan IMD Terhadap Pemberian ASI Eksklusif

\begin{tabular}{|c|c|c|c|c|c|c|c|}
\hline \multirow{3}{*}{$\begin{array}{c}\text { Inisiasi } \\
\text { Menyusu } \\
\text { Dini }\end{array}$} & \multicolumn{4}{|c|}{ ASI Eksklusif } & \multirow{3}{*}{$\begin{array}{c}\begin{array}{c}\text { Jum } \\
\text { lah }\end{array} \\
\mathbf{N}\end{array}$} & \multirow{3}{*}{$\begin{array}{c}\text { p- } \\
\text { value }\end{array}$} & \multirow{3}{*}{$\begin{array}{c}\text { PR } \\
(95 \% \\
\text { CI) }\end{array}$} \\
\hline & \multicolumn{2}{|c|}{$\begin{array}{c}\text { Tidak } \\
\text { ASI } \\
\text { Eksklusif }\end{array}$} & \multicolumn{2}{|c|}{$\begin{array}{c}\text { ASI } \\
\text { Eksklusif }\end{array}$} & & & \\
\hline & $\mathbf{n}$ & $\%$ & $\mathbf{n}$ & $\%$ & & & \\
\hline $\begin{array}{l}\text { Tidak } \\
\text { IMD }\end{array}$ & 71 & 86,6 & 11 & 13,4 & 82 & 0,001 & $\begin{array}{c}1,616 \\
(1,133 \\
-\end{array}$ \\
\hline IMD & 15 & 53,6 & 13 & 46,4 & 28 & & $2,306)$ \\
\hline
\end{tabular}

Berdasarkan tabel diatas Analisis bivariat ini didapatkan nilai ( $p$-value > $0,05=0,001)$ yang berarti bahwa terdapat hubungan yang bermakna antara IMD terhadap Pemberian ASI Eksklusif, di peroleh nilai $\mathrm{PR}=1,616$ yang artinya prevalensi ibu yang tidak IMD kemungkinan untuk tidak memberikan ASI Eksklusif 1,616 kali dibandingkan dengan ibu yang memberikan ASI Eksklusif kepada bayinya.

Tabel 3 Hubungan Pendidikan Terhadap Pemberian ASI Eksklusif

\begin{tabular}{|c|c|c|c|c|c|c|c|c|}
\hline \multirow{3}{*}{$\begin{array}{l}\text { Pendi } \\
\text { dikan }\end{array}$} & \multicolumn{4}{|c|}{ ASI Eksklusif } & \multirow[b]{2}{*}{$\begin{array}{l}\text { To } \\
\text { tal }\end{array}$} & \multirow{3}{*}{$\%$} & \multirow{3}{*}{$\begin{array}{c}p- \\
\text { va } \\
\text { lue }\end{array}$} & \multirow{3}{*}{$\begin{array}{c}\text { PR } \\
(95 \% \\
\text { CI })\end{array}$} \\
\hline & \multicolumn{2}{|c|}{$\begin{array}{l}\text { Tidak ASI } \\
\text { Eksklusif }\end{array}$} & \multicolumn{2}{|c|}{$\begin{array}{c}\text { ASI } \\
\text { Eksklusi } \\
\text { f }\end{array}$} & & & & \\
\hline & $\mathbf{N}$ & $\%$ & n & $\%$ & $\mathbf{N}$ & & & \\
\hline Rendah & 30 & 93,8 & 2 & 6,3 & 32 & 100 & & 1,306 \\
\hline Tinggi & 56 & 71,8 & 22 & $\begin{array}{c}28, \\
2\end{array}$ & 78 & 100 & $\begin{array}{l}0,0 \\
23\end{array}$ & $\begin{array}{r}(1,107 \\
1,541)\end{array}$ \\
\hline
\end{tabular}

Analisis bivariat ini didapatkan nilai $(p$-value $>0,05=0,023$ ) bahwa terdapat hubungan yang bermakna antara pendidikan terhadap Pemberian ASI Eksklusif. Nilai $\mathrm{PR}=1,306$ yang artinya prevalensi ibu yang berpendidikan rendah kemungkinan tidak memberikan ASI Eksklusif 1,306 kali dibandingkan dengan ibu yang berpendidikan tinggi.

\section{Tabel 4 Hubungan Pekerjaan Terhadap Pemberian ASI Eksklusif}

\begin{tabular}{cccccccc}
\hline & \multicolumn{3}{c}{ ASI Eksklusif } & & & \\
\cline { 2 - 5 } $\begin{array}{c}\text { Peker } \\
\text { jaan }\end{array}$ & $\begin{array}{l}\text { Tidak ASI } \\
\text { Eksklusif }\end{array}$ & \multicolumn{2}{c}{$\begin{array}{c}\text { ASI } \\
\text { Eksklusif }\end{array}$} & & Total & \% & $\begin{array}{c}\boldsymbol{p} \text { - } \\
\text { value }\end{array}$ \\
& N & $\%$ & n & \% & N & & \\
\hline $\begin{array}{c}\text { Beker } \\
\text { ja }\end{array}$ & 19 & 70,4 & 8 & 29,6 & 27 & 100 & \\
$\begin{array}{c}\text { Tidak } \\
\text { Beker } \\
\text { ja }\end{array}$ & 67 & 80,7 & 16 & 19,3 & 83 & 100 & 8 \\
\hline
\end{tabular}


Berdasarkan tabel diatas Analisis bivariat ini didapatkan nilai ( $p$-value> $0,05=0,388)$ yang berarti tidak ada hubungan yang bermakna antara pekerjaan terhadap Pemberian ASI Eksklusif.

Tabel 5 Hubungan Pendapatan Terhadap Pemberian ASI Eksklusif

\begin{tabular}{|c|c|c|c|}
\hline \multirow[b]{2}{*}{ Pendapatan } & \multicolumn{2}{|c|}{ ASI Eksklusif } & \multirow[b]{2}{*}{ Total } \\
\hline & $\begin{array}{c}\text { Tidak ASI } \\
\text { Eksklusif }\end{array}$ & $\begin{array}{c}\text { ASI } \\
\text { Eksklusif }\end{array}$ & \\
\hline
\end{tabular}

\begin{tabular}{cccccccc} 
& $\mathbf{N}$ & $\boldsymbol{\%}$ & $\mathbf{n}$ & $\boldsymbol{\%}$ & $\mathbf{N}$ & \\
\hline Rendah & 29 & 90,6 & 3 & 9,4 & 32 & 100 & \\
Tinggi & 57 & 73,1 & 21 & 26,9 & 78 & 100
\end{tabular}

Berdasarkan tabel diatas Analisis bivariat ini didapatkan nilai ( $p$-value> $0,05=0,073)$ yang berarti tidak ada hubungan yang bermakna antara pendapatan terhadap Pemberian ASI

Eksklusif.

Tabel 10 Hubungan Dukungan Keluarga Terhadap Pemberian ASI Eksklusif

\begin{tabular}{|c|c|c|c|c|c|c|c|c|}
\hline \multirow{3}{*}{$\begin{array}{c}\text { Duku } \\
\text { ngan } \\
\text { Keluar } \\
\text { ga }\end{array}$} & \multicolumn{4}{|c|}{ ASI Eksklusif } & \multirow[b]{2}{*}{$\begin{array}{l}\text { To } \\
\text { tal }\end{array}$} & \multirow{3}{*}{$\%$} & \multirow{3}{*}{$\begin{array}{c}p- \\
v a \\
\text { lue }\end{array}$} & \multirow{3}{*}{$\begin{array}{c}\text { PR } \\
(95 \% \mathrm{CI})\end{array}$} \\
\hline & \multicolumn{2}{|c|}{$\begin{array}{c}\text { Tidak } \\
\text { ASI } \\
\text { Eksklusi } \\
\text { f }\end{array}$} & \multicolumn{2}{|c|}{$\begin{array}{c}\text { ASI } \\
\text { Eksklu } \\
\text { sif }\end{array}$} & & & & \\
\hline & n & $\%$ & $\mathbf{N}$ & $\%$ & $\mathbf{N}$ & & & \\
\hline $\begin{array}{l}\text { Tidak } \\
\text { Mendu } \\
\text { kung }\end{array}$ & 28 & $\begin{array}{c}10 \\
0\end{array}$ & 0 & 0 & 28 & 100 & 0.003 & $\begin{array}{c}1,414 \\
(1,130- \\
1,625)\end{array}$ \\
\hline $\begin{array}{c}\text { Mendu } \\
\text { kung }\end{array}$ & 58 & $\begin{array}{c}70, \\
7\end{array}$ & 24 & $\begin{array}{c}29, \\
3\end{array}$ & 82 & & & \\
\hline
\end{tabular}

Berdasarkan tabel diatas Analisis bivariat ini didapatkan nilai ( $p$-value> $0,05=0,003$ ) yang berarti bahwa terdapat hubungan yang bermakna antara dukungan keluarga terhadap Pemberian
ASI Eksklusif. Hasil analisis juga di peroleh nilai $\mathrm{PR}=1,414$ yang artinya prevalensi ibu yang tidak memiliki dukungan keluarga kemungkinan untuk tidak memberikan ASI Eksklusif 1,414 kali dibandingkan dengan ibu yang memiliki dukungan keluarga untuk memberikan ASI Eksklusif kepada bayinya.

\section{pnalisis Multivariat}

value Melakukan seleksi variabel kandidat multivariat. Bila hasil uji bivariatnya mempunyai nilai $p \leq 0,25$, maka variabel tersebut dapat dimasukkan dalam model multivariat. Nilai $p$ setiap variabel independen tersebut dapat dilihat pada Tabel berikut ini:

Tabel 11 Variabel Independen yang masuk dalam Model Multivariat

\begin{tabular}{lc}
\hline \multicolumn{1}{c}{ Variabel } & $\boldsymbol{p}$ value \\
\hline Pendidikan & 0,022 \\
Pekerjaan & 0,261 \\
Pendapatan & 0,054 \\
Inisiasi Menyusu Dini & 0,001 \\
Dukungan Keluarga & 0,998 \\
\hline
\end{tabular}

\section{Pemodelan Multivariat}

Analisis multivariat dalam menggunakan metode ENTER. Tahap selanjutnya melakukan uji konfonding yaitu melihat perubahan nilai OR dengan menggunakan rumus: Perubahan $\mathrm{OR}=$ (OR sebelum variabel terpilih dikeluarkan - OR setelah variabel terpilih 
dikeluarkan) dibagi OR setelah variabel terpilih dikeluarkan dikali $100 \%$. Jika terdapat perubahan nilai OR yang dihasilkan $\geq 10 \%$, maka variabel tersebut tetap berada didalam model, karena merupakan variabel konfonding.

Tabel 12 Model Uji Regresi Logistik

\begin{tabular}{lcccc}
\hline \multicolumn{1}{c}{ Variabel } & SE & Sig & $\begin{array}{c}\text { Exp } \\
(\mathbf{B})\end{array}$ & $\begin{array}{c}\text { 95\% CI Exp } \\
(\mathbf{B})\end{array}$ \\
\hline Pendidikan & 0,930 & 0,468 & 1,963 & $0,317-12,150$ \\
Pendapatan & 0,873 & 0,338 & 2,307 & $0,417-12,776$ \\
Inisiasi & 0,698 & 0,045 & 4,052 & $1,031-15,920$ \\
Menyusu Dini & 0,659 & 0,006 & 0,164 & \\
Konstanta & 0,65 & \\
\hline
\end{tabular}

Uji konfonding didapatkan 3 variabel yang masuk ke model akhir uji regresi logistik yaitu: Pendidikan, Pendapatan, Inisiasi Menyusu Dini (IMD). Variabel IMD yang merupakan variabel yang dominan terhadap pemberian ASI Eksklusif di wilayah kerja Puskesmas Makrayu.

\section{Pembahasan}

\section{Hubungan Inisiasi Menyusu Dini (IMD) Terhadap Pemberian ASI Eksklusif di Wilayah Kerja Puskesmas Makrayu Kota Palembang.}

Berdasarkan analisis bivariat hubungan Inisiasi menyusu dini (IMD) menunjukan ada hubungan yang bermakna antara inisiasi menyusu dini (IMD) terhadap Pemberian ASI Eksklusif (p-value : 0,001$)$, di peroleh $\mathrm{PR}=1,616$ yang artinya prevalensi ibu yang tidak IMD kemungkinan untuk tidak memberikan ASI Eksklusif 1,616 kali dibandingkan dengan ibu yang melaksanakan IMD untuk memberikan ASI Eksklusif kepada bayinya. Hasil uji multivariat binary logistic menunjukan variabel Inisiasi Menyusu Dini (IMD) merupakan variabel yang dominan terhadap Pemberian ASI Eksklusif. Beberapa hal di atas menunjukkan bahwa IMD memiliki peranan penting agar bayi dapat diberikan ASI eksklusif. Akan tetapi, keputusan untuk memberikan ASI eksklusif tidak hanya dipengaruhi oleh IMD. Rendahnya hubungan ini terkait adanya beberapa faktor lain yang mempengaruhi pemberian ASI eksklusif selain IMD. Faktor selain IMD tersebut adalah faktor psikologis dan faktor demografi dari ibu. Faktor psikologis ibu meliputi tingkat pengetahuan ibu, rasa percaya diri ibu (sikap), komitmen ibu untuk menyusui, serta dukungan dari petugas kesehatan.

Dua jam pertama kehidupan bayi adalah waktu yang optimal untuk bayi belajar menyusui. Kontak kulit dengan kulit antara bayi dan ibu pada periode ini meningkatkan kesempatan bayi bisa menyusu di jam pertama kehidupan dan dalam jangka panjang (Agudelo et al, 2016). Pada usia 30 menit bayi dianjurkan untuk disusukan kepada ibunya, bukan untuk pemberian nutrisi tetapi untuk 
belajar menyusu atau membiasakan menghisap puting susu dan juga guna mempersiapkan ibu mulai memproduksi ASI. Apabila bayi tidak menghisap puting susu pada setengah jam setelah persalinan, prolaktin akan turun dan sulit merangsang prolaktin sehingga ASI baru akan keluar hari ketiga atau lebih dan memperlambat pengeluaran kolostrum (Adam, Alim \& Sari, 2016).

Hasil penelitian ini sesuai dengan teori yang ditulis oleh Guyton.A, (2005) setiap kali ibu menyusui bayinya, sinyal saraf dari puting susu ke hipotalamus akan menyebabkan lonjakan sekresi prolaktin sebesar 10 sampai 20 kali lipat yang berlangsung kira-kira 1 jam. Tapi bila laktasi tidak dilakukan terus menerus payudara akan kehilangan kemampuan untuk memproduksi air susu ibu dalam waktusatu minggu atau lebih

Penelitian ini sesuai dengan penelitian YJ Kelly and RG Watt yang dilakukan di UK (2005) hasilnya bayi yang diberi kesempatan melakukan inisiasi menyusu dini, persentase masih menyusunya bayi sampai usia enam bulan adalah $59 \%$ dan sampai bayi usia 12 bulan adalah $38 \%$. Pada bayi yang tidak diberi kesempatan inisiasi menyusu dini, persentase yang masih menyusunya hanya $19 \%$ untuk bayi usia enam bulan dan $8 \%$ untuk bayi usia 12 bulan. Pelaksanaan IMD tentunya membutuhkan kerjasama antara petugas kesehatan yang menolong persalinan dengan ibu dan keluarganya. Setiap tindakan medis tetap harus membutuhkan persetujuan dari keluarga, sebelum IMD dilakukan tetap harus dikonsultasikan kepada keluarga tentang manfaat dan pentingnya ASI. Sosialisasi oleh dokter, perawat dan bidan tentu dapat dilakukan sebelum ibu melahirkan. Misalnya, pada tiap kali kunjungan ANC terutama trimester ke 3, penggunaan media cetak dan visual juga akan membantu sosialisasi IMD di masyarakat

Hasil penelitian ini dapat disimpulkan bahwa lebih dari sebagian ibu tidak melaksanakan IMD hal disebabkan oleh pengetahuan ibu yang masih kurang dan petugas kesehatan yang berpikir bahwa kondisi ibu yang masih lemah, sehingga tenaga kesehatan lebih memprioritaskan perawatan untuk memperbaiki kondisinya. Kurangnya dukungan pada ibu yang sedang bersalin membuat ibu cenderung lebih memilih beristirahat setelah proses persalinan dari pada harus kesulitan membantu mengawasi bayi untuk melakukan IMD. Namun ada beberapa ibu yang tidak melaksanakan IMD tapi memberikan ASI 
Eksklusif hal ini disebabkan oleh sudah baiknya pengetahuan ibu tentang ASI Eksklusif dan adanya dorongan dari keluarga untuk memberikan ASI eksklusif selama enam bulan. Diharapkan kepada petugas kesehatan agar dapat membantu ibu untuk melakukan IMD pasca persalinan, sehingga bayi yang baru lahir dapat terbiasa menyusu kepada ibunya.

\section{Hubungan Pendidikan Terhadap Pemberian ASI Eksklusif di Wilayah Kerja Puskesmas Makrayu Kota Palembang.}

Berdasarkan analisis bivariat terdapat hubungan pendidikan dengan pemberian ASI Eksklusif ( $p$-value 0,023) yang berarti bahwa terdapat hubungan yang bermakna antara pendidikan terhadap Pemberian ASI Eksklusif. Hasil analisis juga di peroleh nilai $\mathrm{PR}=1,306$ yang artinya prevalensi ibu yang berpendidikan rendah kemungkinan untuk tidak memberikan ASI Eksklusif 1,306 kali dibandingkan dengan ibu yang berpendidikan tinggi untuk memberikan ASI Eksklusif kepada bayinya. Berdarkan uji multivariat regresi binary logistic menunjukan bahwa pendidikan merupakan variabel konfonding terhadap pemberian ASI Eksklusif.

Hasil penelitian ini sama dengan hasil penelitian Elinofia (2011) dalam Ratih (2012) yang menyatakan bahwa pendidikan merupakan faktor penting yang mempengaruhi ibu dalam pemberian ASI Eksklusif, pendidikan merupakan suatu kegiatan untuk meningkatkan pengetahuan. Pendidikan dapat diperoleh secara formal, informal dan non formal, dengan demikian semakin tinggi pendidikan ibu semakin mudah ibu untuk memperoleh informasi. Menurut Widiyanti (2008) Ibu yang mendapatkan informasi kurang tentang menyusui dan pentingnya pemberian ASI Eksklusif merupakan salah satu faktor yang menyebabkan rendahnya motivasi ibu dalam pemberian ASI Eksklusif kepada bayinya, sedangkan ibu yang mendapatkan informasi yang benar tentang ASI Eksklusif berpeluang lebih besar untuk menjaga motivasi menyusui bayinya.

Dari hasil penelitian dilapang bahwa semakin tinggi pendidikan seorang ibu maka akan semakin menambah pengetahuan ibu tentang IMD dan ASI Eksklusif sehingga ibu akan melakukan inisiasi menyusu dini kepada bayinya yang baru lahir dan memberikan ASI eksklusif kepada bayi. Begitu juga sebaliknya rendahnya pendidikan seorang ibu membuat pengetahuan ibu menjadi kurang sehingga ibu kurang mengetahui 
tentang inisiasi menyusu dini dan ASI Eksklusif.

\section{Hubungan Pekerjaan Terhadap Pemberian ASI Eksklusif di Wilayah Kerja Puskesmas Makrayu Kota Palembang.}

Berdasarkan hasil bivariat terdapat $p$-value $>0,05=0,388$ yang berarti tidak ada hubungan bermakna antara pekerjaan dengan pemberian ASI Eksklusif. Uji multivariat dengan menggunakan regresi binary logistic menunjukan bahwa pekerjaan bukan merupakan variabel prediktor terhadap pemberian ASI eksklusif. Penelitian ini sejalan dengan Ayutifanie (2015) yang menyatakan tidak ada hubungan antara pekerjaan dengan pemberian ASI Eksklusif dengan nilai p-value 0,510 yang dilakukan di Wilayah Kerja Puskesmas Ambulu, Kabupaten Jember.

Hal ini menunjukan bahwa akan terjadi penurunan pemberiaan ASI Eksklusif jika disertai peningkatan pekerjaan ibu. Pada ibu bekerja, fasilitasi dari perusahaan juga dibutuhkan termasuk alokasi waktu dan tempat mengeluarkan ASI, serta tempat penyimpanan ASI. Hal ini sebetulnya telah didukung dengan peraturan bersama Menteri Negara Pemberdayaan Perempuan, Menteri Tenaga Kerja dan Transmigrasi, dan Menteri Kesehatan tahun 2008 tentang Peningkatan Pemberian Air Susu Ibu selama Waktu Kerja di Tempat kerja. Tetapi aplikasi dan evaluasi dari peraturan ini sejak ditetapkan belum diketahui dan memerlukan kajian lebih lanjut. Sebuah terobosan baru ditemui di Jakarta, yaitu berupa jasa pelayanan kurir untuk mengambil ASI dari tempat ibu bekerja dan di antar ke rumah ibu saat jam kerja. Dalam hal ini semua proses pemerasan, penyimpanan, dan pemberian ASI tersimpan tersebut harus dilakukan sesuai standar (Nainggolan, 2012).

Sedangkan dalam penelitian ini dapat di simpulkan bahwa tidak terdapat hubungan antara pekerjaan terhadap ASI eksklusif karena dilapangan menunjukan bahwa ibu yang bekerja maupun tidak bekerja cenderung tidak memberikan ASI eksklusif yang mungkin dipengaruhi oleh pengetahuan ibu tentang ASI eksklusif dan kurangnya dukungan dari keluarga.

Hubungan Pendapatan Terhadap Pemberian ASI Eksklusif di Wilayah Kerja Puskesmas Makrayu Kota Palembang.

Berdasarkan hasil bivariat dengan $p$-value $=0,073$ yang berarti tidak ada hubungan yang bermakna antara pendapatan terhadap pemberian ASI eksklusif. Hasil multivariat dengan menggunakan uji regresi binary logistic 
menunjukan bahwa pendapatan merupakan variabel konfonding terhadap pemberian ASI eksklusif. Hal ini sejalan dengan penelitian Ayutifanie yang menyatakan tidak ada hubungan antara pendapatan dengan pemberian ASI eksklusif dengan nilai $p=0,170$. Penelitian ini juga sama dengan Anggrita (2010) diperoleh nilai $p=0,166$ sehingga dapat disimpulkan tidak ada hubungan bermakna antara pendapatan dengan pemberian ASI eksklusif.

Rendahnya pendapatan merupakan rintangan yang menyebabkan orang tersebut tidak mampu membeli pangan dalam jumlah yang diperlukan. Sebaliknya, semakin tinggi tingkat pendapatan dalam keluarga justru akan menyebabkan semakin rendahnya persentase dalam pemberian ASI, hal ini dijelaskan sebagai berikut semakin tinggi tingkat pendapatan ibu maka akan tinggi pula daya beli ibu terhadap susu formula, dan tambahan makanan pendamping ASI (Dewi, 2009).

Hasil penelitian dilapangan bahwa pendapatan yang rendah seharusnya lebih berpeluang memberikan ASI Eksklusif kepada bayi, akan tetapi dalam penelitian ini responden yang berpendapatan tinggi justru paling banyak tidak memberikan ASI Eksklusif. Hal ini dikarenakan masih rendahnya pengetahuan ibu terkait inisiasi menyusu dini (IMD) dan ASI Eksklusif, selain itu masih ada beberapa ibu yang bekerja guna membantu suaminya dalam memenuhi kebutuhan keluarga sehingga membuat ibu tersebut tidak dapat memberikan ASI eksklusif dan lebih memilih menggantinya dengan susu formula kepada bayinya.

\section{Hubungan Dukungan Keluarga Terhadap Pemberian ASI Eksklusif di Wilayah Kerja Puskesmas Makrayu Kota Palembang.}

Berdasarkan uji bivariat menunjukan ada hubungan bermakna antara dukungan keluarga terhadap pemberian ASI eksklusif dengan $p$-value= 0,003, di peroleh nilai $\mathrm{PR}=1,414$ yang artinya prevalensi ibu yang tidak memiliki dukungan keluarga kemungkinan untuk tidak memberikan ASI Eksklusif 1,414 kali dibandingkan dengan ibu yang memiliki dukungan keluarga untuk memberikan ASI Eksklusif kepada bayinya. Hasil multivariat dengan menggunakan uji regresi binary logistic menunjukan bahwa dukungan keluarga bukan merupakan variabel prediktor terhadap pemberian ASI eksklusif.

Septiani (2017) mengatakan Keluarga, selain bisa menjadi faktor pendukung sekaligus justru bisa 
menjadifaktor penghambat. Keinginan ibu untukmemberikan ASI eksklusif sebaiknya sudah didiskusikan dengan keluarga terutama orang-orang yang akan tinggal bersama ibu saat bayi itu lahir misal suami, ibu, ibu mertua jauh sebelum si bayi lahir atau minimal saat fase kehamilan. Tanamkan kepada keluarga pentingnya ASI, bagaimana memberikan ASI eksklusif serta dukungan apa yang mereka bisa berikan. Hal ini menjadi penting, karena pada beberapa kasus, kegagalan seorang ibu dalam memberikan ASI eksklusif justru karena pemahaman yang salah dari keluarga, misalnya diberikan air putih supaya bayi tidak kuning, atau menambahkan bayi dengan susu formula karena bayi menangis dan beranggapan bahwa bayi masih lapar dan saat itu si ibu bayi kesulitan menolak atau menentang karena yang memberikan adalah ibu mertua maupun ibu kandungnya. Peristiwa ini akan bisa diminimalisir saat ibu maupun keluarga memiliki pengetahuan tentang ASI yang baik serta kesepakatan dan komitmen yang kuat untuk mendukung ibu dalam memberikan ASI eksklusif.

Berdasarkan penelitian ini dan teori yang ada dukungan keluarga berupa dorongan, motivasi terhadap istri, baik secara moril ataupun materil dan bantuan praktis lainnya akan mempengaruhi emosi istri sehingga secara tidak langsung mempengaruhi produksi ASI, dukungan suami berupa dukungan secara emosional yang mendasari tindakan, hal tersebut akan membuat orang merasa diperhatikan, dicintai, dimuliakan dan dihargai. Dukungan suami terhadap pemberian ASI eksklusif menjadi faktor kunci kesadaran seorang ibu untuk memberikan gizi yang terbaik bagi bayinya.

\section{KESIMPULAN DAN SARAN}

\section{Kesimpulan}

Hasil penelitian didapatkan bahwa ada hubungan bermakna antara Inisiasi Menyusu Dini (IMD), pendidikan, dan dukungan keluarga terhadap pemberian ASI Eksklusif. Berdasarkan hasil multivariat variabel Inisiasi Menyusu Dini (IMD) merupakan variabel yang paling dominan terhadap pemberian ASI eksklusif.

\section{Saran}

Berdasarkan hasil penelitian tersebut, beberapa saran yang dapat diterapkan adalah peran petugas kesehatan khususnya petugas Puskesmas agar lebih meningkatkan program promosi serta pelatihan tentang Iniasiasi Menyusu Dini (IMD) dan ASI eksklusif yang benar dan tepat. Pemerintah 
diharapkan bisa membuat agenda kebijakan tentang kampanye ASI eksklusif sebagai isu penting di media publik, sehingga diharapkan mampu mengubah perilaku publik kedalam perilaku yang lebih positif yaitu perilaku pemberian ASI eksklusif.

Diharapkan juga Kepada Dinas Kesehatan melakukan pengawasan di berbagai fasilitas kesehatan yang ada di Kota Palembang yang melayani persalinan agar memberi kesempatan kepada ibu untuk melaksanakan IMD, rawat gabung dan memberikan ASI secara Eksklusif.

\section{DAFTAR PUSTAKA}

Ayutifanie, Deviana. 2015. Hubungan Antara Inisiasi Menyusu Dini (IMD) Dengan Pemberian ASI Eksklusif Pada Ibu Primipara Dengan Bayi Usia >6-12 Bulan. Artikel Ilmiah Hasil Penelitian Fakultas Kesehatan Masyarakat, Universitas Jember

Desi Ulandari, 2017. Faktor-Faktor yang Mempengaruhi Pelaksanaan IMD pada Pasien Pasca Persalinan di BPM Ratna Wilis Palembang.GASTER Vol. XVI No. 1

Dinas Kesehatan Provinsi Sumsel. 2015. Profil Dinkes Provinsi Sumatera Selatan 2016. Profil Dinkes Provinsi Sumatera Selatan

Dinas Kesehatan Kota Palembang. 2015. Profil Dinkes Kota Palembang Palembang
2017. Profil Dinkes Kota Palembang

Edmond, K.M. 2006. Delayed breastfeeding initiation increase risk of neonatal mortality. Pediatrics. 117 (3).Doi 10.1542/peds. 2005-1496.

Emma, Septian. 2014. Dukungan Tenaga Kesehatan Untuk Meningkatkan Niat Ibu Hamil Dalam Memberikan ASI Eksklusif di Wilayah Kerja Puskesmas Gondokusuman, Kota Yogyakarta. Jurnal Promosi Kesehatan Indonesia Vol. 9 / No. 2 / Agustus 2014. 196

2009. Penyebab Keberhasilan dan Kegagalan Praktik Pemberian ASI Ekslusif. Kesehatan Masyarakat. Jurnal Kesehatan Masyarakat Nasional.

Guyton dan Hall. 2005. Buku Ajar Fisiologi Kedokteran. Jakarta: http: Penerbit Buku Kedokteran EGC.

Hesteria F.A, I.W.G. Artawan Eka Putra,\& Dyah Pradnya Paramita Duarsa. 2016. Faktor-Faktor yang Berhubungan dengan Pemberian ASI Ekslusif pada Ibu Beraktivitas dalam Rumah di Kabupaten Tabanan. Public Health and Preventive Medicine Archive. V.4 No.2.

Hidayat, A.A.A. 2007. Riset keperawatan dan teknik penulisan ilmiah. Ed. 2. Jakarta:Selemba Medika.

Kementerian Kesehatan RI. 2013. Survei Demografi dan Kesehatan Indonesia (SDKI) 2012. Jakarta: Kemenkes RI

2015. Profil Kesehatan Indonesia. Jakarta Kementrian Kesehatan RI.

King, F Savage, 1994. Menolong Ibu Menyusui, Gramedia, Jakarta. 
Notoatmodjo, S. 2003. Pendidikan dan perilaku kesehatan. Jakarta: Rineka Cipta

Riset Kesehatan Dasar. 2010. Badan penelitian dan pengembangan kesehatan kemeterian kesehatan RI

Roesli, Utami. 2005. Mengenal ASI Eksklusif. Jakarta: Trubus Agriwidya 2008. Inisiasi Menyusu Dini Plus ASI Eksklusif. Pustaka. Bunda.Jakarta

2012. Panduan Inisiasi Menyusu Dini Plus ASI Eksklusif. Jakarta: Pustaka Bunda

Siallagan dkk. 2013. Faktor yang Berhubungan Dengan Pemberian Asi Eksklusif Pada Bayi (0-6 Bulan) Di Kelurahan Bantan Kecamatan Medan tembung. Jurnal Fakultas Kesehatan Masyarakat USU

Siregar, Nurhalimah Y. 2003. Hubungan Iklan Susu Formula Di Televisi Dengan Pola Pemberian Asi Pada Bayi di Kelurahan Sidorejo Kecamatan Medan Tembung, Tahun 2003 [serial online]. Sumatera: USU. http://repository.usu.ac.id/handle/12 $3456789 / 35053$

Septiani, Hanulan, Dkk. (2017). FaktorFaktor yang Berhubungan dengan Pemberian ASI Eksklusif Oleh Ibu Menyusui yang Bekerja Sebagai Tenaga Kesehatan. JurnalAisyah: Jurnal Ilmu Kesehatan. 2 (2), 159 174

Siregar A, Pemberian ASI Eksklusif dan Faktor-faktor yang mempengaruhinya, Fakultas Kesehatan masyarakat Universitas Sumatra Utara, 2004.

Smet, Bart. 1994. Psikologi Kesehatan, Gramedia Widia Sarana Indah, Jakarta.
Sugiono. 2011. Metode Penelitian Kuantitatif, Kualitatif dan $R \& D$. Alfabeta cv. Bandung.

Wiknjosastro, Hanifa, 2007. Ilmu Kebidanan. Yayasan Bina Pustaka Sarwono. Prawirohardjo. Jakarta

Widyanti N. (2008) Hubungan antara pengetahuan dan sikap bidan terhadap prakik IMD kepada pasien di Kabupaten Jember. Tesis Program Sarjana bagian PKIP FKM Universitas Jember.

Wulandari, Melly. 2011. Faktor-Faktor yang Berhubungan dengan Pemberian Makanan Prelakteal pada Bayi Baru Lahir di Desa Supat Timur Kabupaten Musi Banyuasin Sumatera Selatan. FKM UIN: Jakarta; 2011.

WHO. 2007. Community Based Strategis for Breastfeeding Promotion and Support in Developing Country, 2009. Global health risks: mortality and burden of disease attributable to selected major risk

http://www.who.int/healthinfo/global_bu rden_disease/globalhealthrisks_repo rt_full.pdf

YJ Kelly and RG Watt (2005) Breastfeeding initiation and exclusive duration at 6 months by social class - results from the Millennium Cohort Study. Public Health Nutrition: 8(4), 417-421

DOI: 10.1079/PHN2004702 